\title{
MIGRANTES, IMIGRANTES E REFUGIADOS: A CLÍNICA DO TRAUMÁTICO
}

\author{
MIGRANTS, IMMIGRANTS AND REFUGEES: THE TRAUMA CLINIC \\ "Miriam Debieux Rosa
}

\section{RESUMO}

Este trabalho visa a apresentar as atividades de extensão universitária realizadas pelo projeto Migrantes, imigrantes e refugiados: vulnerabilidade e laço social, desenvolvido no Instituto de Psicologia da Universidade de São Paulo, assim como seus objetivos, resultados e desdobramentos. Inicialmente, apresentaremos o seu campo epistemológico teórico-clínico de articulação entre Psicanálise, sociedade e política, que põe em foco as relações entre sujeito e os modos de construção de laços sociais. Traçamos alguns elementos para caracterizar os problemas dos imigrantes e refugiados recém-chegados ao país e apresentar algumas das saídas e dos impasses desses sujeitos no laço social. Observamos inúmeras saídas e reorganizações criativas, com articulações entre política e desejo. Destacamos os impasses relativos à angústia, à culpa e à superação das violências, à potência enlouquecedora do trauma e desorganizações subjetivas e à errância sem fim de alguns desses sujeitos. Por fim, apresentamos as coordenadas da clínica do traumático e as estratégias e dispositivos clínicopolíticos desenvolvidos na abordagem desses sujeitos e, particularmente, as questões da demanda e da posição do analista frente às desordens subjetivas geradas por situações políticas e sociais e as estratégias de elaboração coletiva do trauma.

Palavras-chave: Psicanálise. Clínica do traumático. Práticas clínico-políticas.

\section{ABSTRACT}

This paper presents the activities carried out by the university outreach project Migrants, immigrants and refugees: social vulnerability and social bond, developed at the Institute of Psychology, University of São Paulo, as well as its objectives, results and consequences. Initially, we present its clinical-theoretical-epistemological field of articulation with Psychoanalysis, society and politics, aimed at investigating the relations between the subject and ways of building social ties. We trace elements to characterize the problems of immigrants and newly arrived refugees to the country and present some of the issues and impasses of these subjects in the social bond. We observe numerous reorganizations and creative resolutions, with links between politics and desire. We highlight the impasses related to anxiety, guilt and the overcoming of violence, the maddening power of trauma and subjective disorganization, as well as the endless wandering of some of these subjects. Finally, we present the coordinates of the trauma clinic and the strategies and clinical-political devices developed in dealing with these subjects, particularly the issues of demand and the analyst's position vis-à-vis disorders generated by subjective political situations and the strategies for the collective elaboration of the trauma.

Key words: Psychoanalysis. Trauma clinic. Clinical-political practices.

* Psicanalista, professora dos programas de pós-graduação em Psicologia Social da Pontifícia Universidade Católica de São Paulo (PUC-SP) e em Psicologia Clínica do Instituto de Psicologia da Universidade de São Paulo (IP-USP), coordenadora do Laboratório Psicanálise e Sociedade e do projeto Migração e Cultura do IP-USP - R. Joaquim Eugênio de Lima, IO4I, ap. 72 - São Paulo - SP - OI4O3-000-e-mail: debieux@terra.com.br. 


\section{INTRODUÇÃO}

O projeto Migração e cultura trabalha a partir da experiência de sujeitos afetados diretamente por fatos sociais e políticos que levam à exclusão, à segregação e consequente emigração ou exílio do país de origem e busca de refúgio em país estrangeiro. Insere-se na proposta ético-política do Laboratório Psicanálise e Sociedade, do Instituto de Psicologia da Universidade de São Paulo (IP-USP), e do Núcleo de Estudos e Pesquisa Psicanálise e Política do Programa de Pós- Graduação de Psicologia Social, da Pontifícia Universidade Católica de São Paulo (PUG-SP). Nosso objetivo principal é estabelecer espaços de intervenção com essa população, objetivando elaborações singulares e grupais e apontando as diferentes possibilidades de reconstituição de laços sociais, favorecendo os vínculos afetivos e de trabalho, de modo a possibilitar, revisar e elaborar formas de viver os "novos contextos". Revisando e rememorando suas histórias e acidentes de vida, é possível a elaboração do luto do exílio, a partir do qual o imigrante, migrante, refugiados e "retornados" possam constituir vínculos com a cidade.

O projeto teve seu início em 2004, a partir do projeto de pós-doutorado História, clínica e a cultura em Psicanálise, de Taeco Toma Carignato. Trabalhamos com várias instituições voltadas ao acolhimento dessas pessoas e, no decorrer dos anos, solidificamos uma parceria com a Casa do Migrante, albergue que acolhe migrantes do Brasil, imigrantes do Cone Sul e africanos que pleiteiam a condição de refugiados. É uma instituição gerenciada por padres escalabrinianos, voltados para essa temática, que atuam em parceria com a Pastoral do Migrante, na cidade de São Paulo.

O projeto foi inscrito no Fundo de Cultura e Extensão Universitária da Universidade de São Paulo inicialmente como Migração e cultura: experiências de atendimento a pessoas em situações de vulnerabilidade psíquica e social e tem se desdobrado em vários aspectos da questão. Nomeado também como Migração e cultura: intervenções psicanalíticas clínico-políticas com migrantes, imigrantes e refugiados, atualmente (20II-20I2) segue como Migrantes, imigrantes e refugiados: vulnerabilidade e laço social. Neste último, ampliamos consideravelmente seus objetivos e, além da parceria com a Casa do Migrante, visa a fazer levantamentos de viabilidade e modos de implementar um serviço ou atividades de atendimento e intervenção junto aos imigrantes, à população e implantar atividades de integração com os estudantes estrangeiros da Universidade.

Constituímos uma equipe sólida e comprometida com o trabalho que contou, além da coordenação do projeto, com a supervisão de mestrandos e doutorandos, destacando as atuais doutoras Sandra Berta, Taeco Carignato e Sandra Alencar, assim como o trabalho de Christian Haritçalde, hoje mestrando do IP-USP. Contamos com a participação de estagiários da graduação e pós-graduação da PUG-SP e da USP e trabalhamos com supervisões e reuniões clínicas. Temos nos tornado referência, através da prática transformada em teses, dissertações, artigos e trabalhos apresentados na área de atendimento psicanalítico fora dos enquadramentos tradicionais, em situações de precariedade e urgência.

\section{PSICANÁLISE, SOCIEDADE E POLÍTICA: CONTEXTO CLÍNICO E EPISTEMOLÓGICO}

O projeto de extensão tem sua base conceitual e clínica nos fundamentos, ética e clínica psicanalíticos, mais particularmente na articulação entre Psicanálise, sociedade e política. Faz parte das atividades do Laboratório Psicanálise e Sociedade do IP-USP e do Núcleo de Estudos e Pesquisa do curso de pós-graduação em Psicologia Social da PUG-SP. Nestes, Psicanálise, sociedade e política são termos que relançam e explicitam a articulação do sujeito com o desejo, o gozo e a dimensão dos laços sociais como laços discursivos. A perspectiva do inconsciente como discurso do Outro, tal como cunhada por Jacques Lacan [9] ganha destaque em seus desdobramentos - o inconsciente é a história, a história da criança na família, da família no campo sociopolítico: o inconsciente é a política [I4].

A problematização da articulação sujeito e enlaçamento social lança-nos na perspectiva da Psicanálise implicada, ou seja, é pela escuta dos sujeitos situados precariamente no campo social que construímos as teorizações sobre os modos como são capturados e enredados em seu desejo e gozo na máquina do poder, de modo a terem suspenso seu lugar discursivo. Essa articulação visa a evidenciar os efeitos, por vezes trágicos, do modo em que o discurso social e político, carregado de interesses e sede de poder, se traveste de discurso do Outro para capturar o sujeito em suas malhas - seja 
na constituição subjetiva, seja nas circunstâncias de destituição subjetiva. Este aparece como um discurso hegemônico, referido à lei do mercado, aparentado a um Outro consistente/não castrado, regido por uma voracidade por vezes de uma violência obscena e interessado na manutenção sociopolítica. Visa a confundir o impossível (falta) com o proibido (lei), para governar o sujeito e sua trajetória na cena familiar, na cena social e política, incidir sobre seu luto, seu enlace em novos grupos e sua reorganização subjetiva, seu embate com a lei. A direção de nossa escuta visa a que o sujeito não se equivoque nesse artifício e tome esse discurso como simbólico, nem que possa recobrir com tal discurso o real, sem espaço para o enigma. É fundamental escutar e separar o enredamento da alienação estrutural ao discurso do Outro das artimanhas ideológicas do poder. Esse enredamento nos processos de constituição e de destituição do sujeito pode ser elucidado pela via da historização dos laços sociais em dados grupos sociais.

O eixo das pesquisas que desenvolvemos está no mal-estar na transmissão (de valores e da história) e no laço social (constituição e destituição) na contemporaneidade. Temos pesquisado e produzido particularmente sobre: as expressões da violência; os efeitos e as dimensões coletivas do trauma, do desamparo e da violação de direitos; as modalidades de resistência e enfrentamento dos sujeitos em situações de violência/ vulnerabilidade; a construção/ transformação do laço social na contemporaneidade; imigração e migração, e o desenvolvimento de práticas clínico-políticas de intervenção. Os projetos de pesquisa são articulados aos dispositivos de pesquisa-intervenção psicanalítica com populações em situação de vulnerabilidade social. Para indicar nossa posição metodológica, citamos Rosa e Domingues, que afirmam:

[...] no caso da contribuição da psicanálise ao estudo do campo social e político, não lhe cabe a pretensão de esgotar, por si só, o fenômeno: cabe-lhe esclarecer uma parcela dos seus aspectos, ainda que uma parcela fundamental. Sem pretensão de substituir a análise sociológica, cabe à Psicanálise incidir sobre o que escapa a essa análise, isto é, sobre a dimensão inconsciente presente nas práticas sociais. [I9]

\section{CASA DO MIGRANTE: OS RECÉM-CHEGADOS E CENAS NESSE ESPAÇO INSTITUCIONAL}

O objetivo da Casa do Migrante é acolher migrantes brasileiros recém-chegados, imigrantes e refugiados e indivíduos envolvidos no drama mundial da mobilidade humana, sem distinção de sexo, etnia, cor, credo, nacionalidade ou qualquer outra forma passível de discriminação. A nomeação casa está referenciada na filosofia de trabalho da Missão Escalabriniana junto aos migrantes, buscando propiciar um "ambiente familiar" no qual as pessoas possam se relacionar e assumir suas responsabilidades perante o próximo. A Casa tem cem leitos, distribuídos num edifício que, antigamente, funcionava como convento, localizado ao lado da Pastoral do Migrante, onde uma equipe jurídica assiste aos migrantes e imigrantes.

$\mathrm{Na}$ Casa estão presentes pessoas de todos os lugares do mundo; diferentes culturas e línguas, diversas religiões e credos. Em um grupo tão heterogêneo é difícil estabelecer qualquer tipo de unidade, a não ser o fato de estarem em condições precárias. São pessoas com vivências turbulentas e violentas: imigrantes, particularmente os latino-americanos, que se perdem nos percalços do deslocamento; migrantes brasileiros que percorrem o país em busca de trabalho ou simplesmente vagueiam, porque não conseguem ou não querem fixar-se em contextos familiares ou comunitários; refugiados, banidos de seus países pela violência e pela miséria.

$\mathrm{Na}$ situação crítica em que estão, nomeiam necessidades muito claras, que podemos ordenar desta forma: a legalização de sua permanência no país, trabalho, aprender a nova língua, moradia ou, como dizem, casamento. Segundo dados do site da Casa do Migrante, os albergados foram se modificando em termos de perfil: aos migrantes internos, que até o ano de 1997 representavam 93\% dos que passavam pela instituição, atualmente agregam-se, numa tendência crescente, os imigrantes, sobretudo dos países andinos e do Cone Sul e, mais recentemente, africanos, estes últimos pleiteando a condição de refugiados.

A presença nessa casa de imigrantes e/ou refugiados no dia a dia é superior a 50\%, o que se deve ao fato das maiores dificuldades enfrentadas pelos mesmos, acarretando um tempo de permanência maior na Casa do Migrante. 


\section{SEM DOCUMENTO: EM BUSCA DE REFÚGIO OU ASILO}

Muitos dos albergados da Casa chegam sem documentos e buscam por refúgio que, no entanto, tem regras muito específicas e que não abrangem muitos deles. Segundo o Alto Comissariado das Nações Unidas para Refugiados (ACNUR) e considerando a Convenção e o Protocolo relativo ao assunto $\dagger$, o refugiado é aquele que:

[...] temendo ser perseguido por motivos de raça, religião, nacionalidade, grupo social ou opiniões políticas, se encontra fora do país de sua nacionalidade e que não pode ou, em virtude desse temor, não quer valer-se da proteção desse país. [I]

Também pode ser concedido o status de refugiado ao cidadão estrangeiro que, devido uma grave e generalizada violação de direitos humanos, é obrigado a deixar o seu país.

A decisão pelo reconhecimento do status de refugiado é de competência do governo brasileiro, por meio do Comitê Nacional para Refugiados (CONARE). Aqueles que não forem considerados refugiados e, portanto, não necessitarem de nenhuma outra forma de proteção internacional, poderão ser repatriados aos seus países de origem. Durante deslocamentos em massa de refugiados - geralmente como resultado de conflitos ou violência generalizada, em contraste à perseguição individual -, não há capacidade para conduzir entrevistas de asilo individuais para todos que cruzarem a fronteira. Tais grupos são frequentemente declarados refugiados prima facie.

Por ser um processo longo, muitos refugiados passam a pedir asilo. Segundo o ACNUR, o requerente de asilo é alguém que afirma ser um refugiado, mas que ainda não teve seu pedido avaliado definitivamente. Os sistemas nacionais de asilo existem para determinar quais requerentes realmente se qualificam para proteção internacional.

O "refúgio" é o caso de alguns dos albergados da Casa, principalmente os refugiados dos conflitos e das guerras étnicas nos países africanos. Além destes, são frequentes os fugitivos da guerra civil na Colômbia.

$\dagger$ Convenção sobre o Estatuto do Refugiado, de I95I, e Protocolo sobre o Estatuto do Refugiado, de I967, ambos patrocinados pelo ACNUR.
Os refugiados recebem um tratamento diferenciado na Casa, que se torna um status almejado por muitos de seus migrantes.

\section{ESTRANGEIROS NA PRÓPRIA PÁTRIA}

Há um número sempre expressivo de migrantes na Casa, vindos de outros estados e de condições de muita pobreza. Chama atenção a situação cultural precária e o fato de que têm a formação escolar e cultural distantes de sua realidade. Também não se ancoram nas suas tradições e história. A depressão e o alcoolismo são recorrentes, junto com o relato de fracassos dos sonhos profissionais e amorosos.

Sua precariedade os faz, nesse contexto, ansiar pelo status de imigrante, principalmente de refugiado, tal como se revela no incidente relatado por um estagiário: "No domingo das eleições, Júlio desceu atrasado para o café da manhã. A cozinheira recusou a servi-lo, alegando estar de saída para votar. Júlio discutiu com a moça. Provocou-a dizendo que 'teria de pintar o rosto de preto para ser atendido'”. Em uma clara alusão aos africanos, o brasileiro diz sobre a sua condição de desterrado em sua própria pátria. Os brasileiros contrastam com os abrigados vindos da África, que costumam falar com empolgação sobre seu país, sua cultura.

\section{CRIANÇAS ESTRANGEIRAS E SUAS MÃES}

A Casa tem recebido muitas mães sozinhas com seus bebês ou crianças pequenas, além de algumas famílias. Temos desenvolvido intervenções com essas pessoas. A criança atravessa a fronteira da língua e a estranheza dos diferentes traços físicos e, através da dimensão lúdica, facilita a interação entre as pessoas da Casa. Por outro lado, conflitos culturais - logo traduzidos por preconceitos ocorrem frente ao modo de conceber os cuidados com as crianças, o que é qualificado como descuido ou indiferença frente às diversidades culturais. Esse ponto tem sido trabalhado por nossa equipe.

\section{LÍNGUAS E CULTURAS}

A convivência com muitas culturas, religiões, línguas e valores no espaço físico da Casa nem sempre é tranquila. Por vezes, essas diferenças desencadeam conflitos, brigas e desentendimentos, gerando expulsões ou abandono do lugar, pois ferem aqueles que são criticados por seus modos de existência.

Alguns dos refugiados concluíram o Ensino Superior, conhecem a situação política do seu país, falam com 
orgulho de sua cultura e têm muito interesse em aprender a língua do país que os abriga. Outros têm dificuldades na adaptação às rotinas e sofrem choques religiosos e culturais. Desenvolvemos estratégias para criar pontos comuns entre os abrigados, desfocando as diferenças, tais como: grupo de recém-chegados, oficinas de Português, a oficina Costurando caminhos para a cidade, entre outros.

\section{IMPASSES E DIREÇÕES DO SUJEITO E O CAMPO POLÍTICO}

Fizemos uma breve e incompleta descrição da situação dos imigrantes, migrantes e refugiados que conhecemos na Casa do Migrante. Nossa experiência com eles permitiu-nos testemunhar, acompanhar e intervir nos diferentes modos de lidar com os impasses desses sujeitos em seu laço social.

Muitos modos ou soluções frente ao laço social são construídos e gestados pelos migrantes. Vemos mulheres que encontram na maternidade de um filho brasileiro o modo de legalização de si mesmas e da família; outras conseguem recusar posições de vítimas de violência de seus maridos ancoradas na nova inserção cultural. Outros desenvolvem novas trajetórias de trabalho, alguns dedicados aos cuidados e assistência a outros imigrantes; alguns iniciam novas aptidões, embora a maior parte das pessoas se dedique aos trabalhos de comércio ambulante. Alguns fazem parcerias para acomodações conjuntas. O casamento com brasileira ou brasileiro é visto como uma saída interessante para resgatar o vínculo e inserir-se na nova terra. Enfim, invenções ou recuos, caminhos possíveis para alinhavar a nova existência à dimensão fantasmática que situa o sujeito e seu lugar de fala.

No entanto, pudemos distinguir alguns processos que suspendem as elaborações dos deslocamentos e sofrimentos e exigem práticas específicas. Ressaltamos a angústia, a culpa frente às violências sofridas por alguns dos abrigados que atendemos, vindos de situações de guerra, conflitos ou pobreza e abandono em seu país de origem. Exemplificamos com Isac (nome fictício) que, ao voltar ao lar - onde vivia com a sua família, africanos do Congo - com um de seus irmãos, encontraram-no incendiado por rebeldes, juntamente com os pais e outros irmãos. Em pânico, eles fogem para diferentes direções para garantir chances de sobrevivência de, ao menos, um deles. Isac pega um navio e vem parar no Brasil. Tem insônia e crises de angústia com as imagens da casa incendiada. Considera que seu maior sofrimento é não saber o destino ou paradeiro do irmão e não ter como ou onde procurá-lo. Outro exemplo é Nahib, que quer morrer e tenta se matar. Depois de ter os seus pais assassinados por questões políticas em Angola, foge, e ao chegar ao Brasil, tem a notícia de que as duas irmãs que ficaram no país também foram mortas.

Essas situações remetem à angústia intensa frente à perda de laços afetivos fundamentais à segurança subjetiva das pessoas, muitas vezes relacionada à culpa, experiência descrita sobre os sobreviventes do Holocausto. Além das dores e humilhações a que são expostos, sobrevêm questões sobre sua própria ética e a culpa sobre o desfecho dos seus familiares, com dúvidas sobre sua possibilidade de sobreviver enquanto os outros morreram. Crises de angústia, desejo de morte e tentativas de suicídio nos demandam intervenções urgentes para esses casos. Nossos manejos buscam relançar o sujeito em sua trajetória e história. Como resultado, pudemos testemunhar como alguns passavam a dizer "não posso morrer", seja para testemunhar o ocorrido, seja para dar andamento à trajetória da família.

Outros casos remetem-nos a abalos psíquicos estruturais e impossibilidades de reorganização. A questão diagnóstica nesses casos não pode ser fechada, supondo haver estrutura previamente psicótica que explicasse as dificuldades destes sujeitos, sob pena de desconsideração dos efeitos disruptivos das situações traumáticas.

Destacamos também outros casos que transformam o exílio forçado pela violência, abandono ou miséria em uma errância sem fim. Algumas pessoas chegam à Casa do Migrante intensificando e eternizando a sua condição de "estar de passagem", ou seja, sem intenção de se fixar em São Paulo ou outro lugar. Um estagiário relata a conversa com um imigrante sul americano que dizia estar de passagem, que viajaria para inúmeros países, pois trabalhava como vendedor itinerante de artefatos que ele mesmo produz. Um refugiado comentou que não sabia como o itinerante conseguia viajar tantos países sem conhecer sua língua e que o achava muito corajoso; achava-se incapaz de tal aventura. O vendedor respondeu que vivia de sua arte e que não precisava dominar a língua do país. $\mathrm{O}$ diálogo causou estranheza na medida em que o termo "coragem" surgiu de quem fugiu de um ambiente de guerra e da morte para vir para o Brasil. 
O corte e o abalo provocado pela ruptura dos laços são repetidos e passa a ser contado pelo sujeito como um modo de vida - chegam e logo pensam no próximo destino, sempre transitório, independendo da idade, de projetos de vida, de laços com os outros. Ao menor sinal de angústia provocam deslocamentos, sem ponto de báscula, a que foram inicialmente lançados de modo involuntário [I8].

\section{PRÁTICA PSICANALÍTICA CLÍNICO- -POLÍTICA E CLÍNICA DO TRAUMÁTICO}

Vamos destacar brevemente as coordenadas da clínica do traumático e as práticas clínico-políticas desenvolvidas no trabalho com esses sujeitos. Nossa prática psicanalítica tem elegido escutar as vidas secas [I6] - pessoas vivendo em situação de miserabilidade, adolescentes em conflito com a lei e pessoas que passam por experiências de desenraizamento (imigrantes, migrantes não documentados, refugiados). Entendemos que o trabalho com sujeitos afetados diretamente pelas situações sociais críticas permite desvendar as artimanhas do poder e o enredamento do sujeito pela via da lei, desejo e gozo. Como decorrência, permite construir práticas clínico-políticas, ou seja, dispositivos e estratégias de resistência aos processos de alienação social.

Formulamos as bases para a clínica do traumático $[4, \mathrm{I} 6, \mathrm{I} 7]$ a partir dos casos em que o sujeito não construiu ainda uma resposta metafórica, um sintoma através do qual possa falar de seu sofrimento e endereçar uma demanda. Pudemos identificar nos sujeitos que se confrontam com a face obscena do Outro uma perda do laço identificatório com o semelhante, um abalo narcísico que o lança à angústia e ao desamparo discursivo que desarticulam sua ficção fantasmática e promovem um sem-lugar no discurso, impossibilitando-os do contorno simbólico do sintoma e de construir uma demanda.

O excesso de consistência do acontecimento ou dito de outro modo, o embate com a violência obscena do Outro - lança o sujeito na condição de "não poder não recordar" (modo como Giorgio Agamben [2] descreve a condição de pessoas nos campos de concentração). Trata-se de um impedimento do esquecimento, do recalque necessário para separar-se do acontecimento. A angústia surge justamente quando não há distância entre a demanda inconsciente e a resposta do Outro, quando se perde a distância entre o enunciado e a enunciação. A angústia, nesses casos, apresenta-se não como manifestação sintomática (caso da angústia neurótica em Freud), tampouco como fuga, mas como um tempo no qual o sujeito custa a se localizar e que, por esta razão, é vinculado ao sentimento de estranheza, o Unheimlich freudiano [6].

Esse tempo no qual o sujeito custa a se localizar tem efeitos em sua posição subjetiva e no laço social. Tais condições se traduzem num silenciamento: silenciado sob o signo da morte, o sujeito é fadado a vagar sem pouso, sendo-lhe vedada a experiência compartilhada, a posição de passador da cultura [8].

Em situações de violência pode haver a suspensão do luto e uma posição melancólica em que o sujeito não nomeia a dor, que não passa. E, muitas vezes, no lugar do significante que possibilite apresentar a ausência do Outro sob um véu, apresentam-se imagens ao modo da loucura individual ou coletiva [12].

Esse silêncio, a dor e a falta de uma demanda são as vicissitudes do psicanalista nessa clínica. Se não há demanda, se a dor é presumida pelos fatos e pelo vazio do silencio, o que sustenta a posição do analista? Que direção dar a essa clínica?

\section{UMA DIREÇÃO POSSÍVEL DE TRATAMENTO: ÉTICA E POLÍTICA}

Para trabalhar a relação trauma, luto, experiência e transmissão, formulamos uma direção possível de tratamento que incide na direção da transformação do trauma em experiência compartilhada e na construção da posição de testemunha, transmissor da cultura. Além disso, faz-se necessário utilizar práticas que levem em consideração as precondições sociopolíticas e subjetivas necessárias para a elaboração do luto e fazer valer a dimensão do desejo, a melhor defesa contra o gozo mortífero [3, 4].

Essas estratégias visam a restituir um campo mínimo de significantes, referidos ao campo do Outro, que possam circular. Isso possibilita ao sujeito localizar-se e poder dar valor e sentido à sua experiência de dor, articulando um apelo que o retire do silenciamento. Existe uma diferença fundamental entre o silêncio mortífero e o silêncio sintomático. Sintomatizar o silêncio - cavado na angústia, no instante perpétuo, no estado melancólico - é a isso que apontamos nesse tipo de intervenções clínicas. É fato: para tratar o trauma provocado pela intervenção do Outro 
totalitário que pretende reduzir os homens a restos, em que se tenta apagar todas as marcas da subjetividade, é necessária uma elaboração que finque suas bases na reconstituição do laço social que norteia o funcionamento do campo social.

Como abordar a questão da angústia e do luto, tanto considerando a produção sociopolítica da angústia, como o impedimento político do processamento subjetivo das situações traumáticas?

Sob o efeito destrutivo de situações traumáticas os sujeitos podem:

- desarticular sua ficção fantasmática;

- perder o laço identificatório dos semelhantes para com eles - estes tendem a recuar diante do terror - com o que perdem a sua solidariedade e são lançados fora da política.

Tais condições promovem, como dissemos, um sem-lugar no discurso, impossibilitando os sujeitos de construir uma demanda - o que se traduz num silenciamento, sob o signo da solidão e da morte.

O que está em jogo é a potência enlouquecedora do traumático, pois, segundo Pujó, o encontro com o mesmo, em repetição sem maior deslocamento ou metaforização, desnuda a incoercível resistência do trauma à sua tramitação. As condições de degradação põem em destaque a necessidade vital de velamento do caráter mortificante do impacto pulsional, ou seja, "a necessidade de faltar ao Outro ali onde o sujeito experimenta-se gozado" [I5].

Nas guerras, com ou sem nome, trava-se outra guerra entre a resistência do sujeito e a resistência do trauma e sua insistência em enlouquecer o sujeito de sua completude. Abordaremos as intervenções que podem criar condições de alterações do campo simbólico - subjetivo, social e político. Ressaltamos que a Psicanálise pode comparecer com elementos para favorecer modos de resistência à instrumentalização social do gozo, à manipulação da vida e da morte no campo social - um terrorismo do ponto de vista do poder soberano.

\section{DO TRAUMA À EXPERIÊNCIA COMPARTILHADA}

Isac viu-se diante de um impasse que exigiu uma resposta em face do horror que a ele se apresentou: salvou sua vida com a fuga do país. A escolha de Isac precipitou-o em um para aquém da fantasia ou da culpa. Paralisado na perenidade traumática, fica sem lugar, de onde poder falar. Parte do país, mas não se parte, não se divide, não se separa. No silêncio mortífero do exílio, fica reduzido a ser passa-dor, mensageiro da morte e do fracasso. Perde a vida na modalidade bios para ficar remetido à vida nua, na modalidade zoé. Mais ainda, perde o laço identificatório dos semelhantes para com ele, sua solidariedade, pois tendem a recuar diante do horror, tal como veremos e que foi abordado por Agamben [2] através da figura do "muçulmano".

De modos diversos, os autores convergem para demonstrar como esse efeito subjetivo é parte da estratégia do poder que abala a potência da experiência compartilhada que escreveria a história do sujeito e da comunidade e, desta forma, lança o sujeito aparentemente fora da política, remetido à vida nua e à sua modalidade puramente biológica.

Em seu livro Lo que queda de Auschwitz, Agamben [2] apresenta a figura do "muçulmano" - nome que designava os mortos-vivos nos campos de concentração, emblemática do estado limite a que chegaram algumas pessoas e que pode expressar uma alegoria da condição de exclusão [2I]. A partir destas considerações, pudemos pensar que a condição desse muçulmano de "não poder não recordar" faz pensar em um impedimento do esquecimento, do recalque necessário para separar-se do acontecimento. O excesso de consistência do acontecimento lança o sujeito num monótono e desesperador presente.

Para recompor um lugar discursivo, para que se faça laço social, é preciso re-construir a história perdida na memória, re-construção que já implica uma deformação, permitindo o luto e uma resposta à ficção, uma reinterpretação do passado. Consideramos que concebidas assim, infância e experiência constituem pressupostos éticos que transcendem o campo ideológico, dizendo respeito antes ao domínio da política (o laço com os outros) e da cultura (a relação ao Outro). Talvez, com Slavoj Žižek, referindo-se à ética da Psicanálise, possamos considerar que:

É preciso arriscar e decidir [...]. Não busque apoio em nenhuma forma de Outro maiúsculo - mesmo que esse Outro maiúsculo seja totalmente vazio. É preciso arriscar o ato sem garantias. Nesse sentido, o fundamento supremo da ética é político. [23]

Aqui se subverte a relação que empalidece a 
política em face da ética ou que inverte onde a ética dá fundamento à política. Ele diz que:

Em Lacan, a ética despolitizada é uma traição ética, porque significa confiança em alguma imagem do grande Outro. Mas o ato lacaniano é, precisamente, o ato em que se presume que não existe grande Outro. [23]

Passar por acontecimentos em relação aos quais não se tem a menor possibilidade de reconhecimento - pois se passa ao largo do imaginável ou imaginarizável - leva a novo impasse ético e clínico. É um impasse que implica não a responsabilização do sujeito, mas o rompimento com esse campo simbólico; não o assentimento subjetivo de sua participação, mas a supressão de qualquer participação neste gozo. Este é um ponto que distingue a direção do tratamento e exige outros dispositivos para além da clínica do sintoma.

A partir destas considerações, pode-se conceber um trabalho clínico que possibilite a construção da posição de testemunha, transmissora da cultura, como diz Jacques Hassoun [8], que componha a trama ficcional pela elaboração não-toda do luto impossível de significar, na transformação do trauma em experiência compartilhada. Tais práticas passam pela elaboração coletiva do trauma, criando condições de alterações do campo simbólico, incluídas as dimensões sociais e políticas.

Restituir um campo mínimo de significantes que possam circular, referidos ao campo do Outro, permite ao sujeito localizar-se e poder dar valor e sentido à sua experiência, articulando um apelo que o retire do silenciamento. Está em jogo não somente a reconstituição narcísica de sua imagem, mas também a recomposição do lugar a partir do qual se vê amável para o Outro (referimos ao Ideal do Eu), reafirmando uma posição que lhe permita localizar-se no mundo e estabelecer laços sociais, inclusive os analíticos.

Passar por acontecimentos em relação aos quais não se tem a menor possibilidade de reconhecimento pois se passa ao largo do imaginável ou imaginarizável - leva a novo impasse ético. É um impasse que implica não a responsabilização do sujeito, mas o rompimento com esse campo dito simbólico; não o assentimento subjetivo de sua participação, mas a supressão de qualquer participação neste gozo - aqui entra a dimensão coletiva.

Tais práticas passam pela elaboração coletiva do trauma [20], criando condições de, através da recuperação da história social e política, da explicitação das distorções, omissões dos interesses e poderes em jogo, possa-se proceder a alterações do campo imaginário e simbólico em que o sujeito possa se situar em uma história, reconstituindo o campo ficcional.

Lacan, discutindo sobre Hamlet, oferece a base teórica para tratar da perda que, rejeitada no simbólico, reaparece no real. Lacan destaca a dimensão ritual e coletiva como precondição à elaboração individual do luto. Diz: "Os ritos são a intervenção maciça de todo jogo simbólico - uma satisfação dada ao que se produz de desordem em razão da insuficiência dos significantes para fazer face ao buraco criado na existência" [I2].

Para tratar o trauma provocado pela intervenção do Outro totalitário, que tenta apagar todas as marcas da subjetividade, é necessária uma elaboração que finque suas bases na reconstituição das leis que norteiam o funcionamento do campo social. Por essa razão, sustentamos que todo fenômeno social traumático deve ser inscrito e elaborado no nível coletivo, sem desmerecer as respostas singulares.

A clínica do traumático lança desafios e exige intervenções não convencionais - que caracterizamos como prática psicanalítica clínico-política - para abordar a questão da angústia e do luto em sua face política, ou seja, considerando a produção sociopolítica da angústia e os processos de impedimento dos processos subjetivos do luto.

Essas precondições podem ser realizadas na clínica, strictu sensu ou através de práticas coletivas que permitam a produção de um ato que toca dimensões do real, simbólico e imaginário, contornando e significando aquilo que, por vezes, é negado socialmente. Só então é possível desidentificar o acontecimento, para que trace um futuro para todos e se torne um emblema cultural.

\section{A POSIÇÃO DO ANALISTA}

A oferta de uma escuta que "supõe romper barreiras e resgatar a experiência compartilhada com o outro, deve ser uma escuta como testemunho e resgate da memória" [I7]. Uma escuta em que se utiliza a presença e a palavra. Uma presença em que o analista é convocado a suportar e servir de mola ao relançamento das significações. Nesse sentido, em nossa clínica, a "presença da palavra" que se suporta pela "presença do analista" ocorre na diversidade das intervenções: em atividades grupais sobre várias temáticas, em oficinas 
de Português, em escutas singulares, na publicização dos acontecimentos e conflitos nas instituições e vida social.

A clínica do traumático convoca o analista a tencionar um espaço entre enunciado e enunciação, abrindo espaço para a fala, declarar "diga mais" e, a partir daí, possibilitar as condições necessárias para a localização subjetiva.

A posição do analista assim é destacada por Berta:

A partir de Lacan, proponho ler esta "pressão", a respeito daquilo que funda no discurso analítico - sua ética: o Desejo do Analista. O analista, além de oferecer sua presença como implicação de escuta, além de decifrar o desejo como desejo do Outro, deve, mantendo seu desejo em $\mathrm{x}$, ser suporte desse objeto, promovendo assim a resposta do analisado a esse enigma, "o que se põe em ato" que convoca a presentificação da pulsão. "Se a transferência é aquilo que da pulsão separa a demanda, o desejo do analista é aquilo que a leva de volta à pulsão". [5]

Esta é uma posição pela qual se paga, alerta Lacan:

[...] pagar com palavras, sem dúvida, se a transmutação que elas sofrem pela operação analítica as eleva a efeito de interpretação;

[...] pagar também com sua pessoa, na medida em que, haja o que houver, ele a empresta como suporte aos fenômenos singulares que a análise descobriu na transferência;

[...] pagar com o essencial em seu juízo mais íntimo, para intervir numa ação que vai ao cerne de seu ser. [IO]

Apresentamos o trabalho e a elaboração de uma prática psicanalítica que contribui para emergência de um sujeito que se separa dessa ordenação, para comparecer como quem questiona essa ordem e se movimenta, criando ações de transformação. Nessa dimensão, é reconhecendo-se como falta-a-ser que a alteridade, a diferença não é significada como ameaça, mas como encontro, com o qual se faz o novo.

\section{REFERÊNCIAS BIBLIOGRÁFICAS}

[I] ACNUR. Deslocando-se através das fronteiras. Disponível em <http://www.acnur.org/t3/portugues/a-quem-ajudamos/refugiados $>$. Acesso sem data.

[2] AGAMBEN, G. Lo que queda de Auschwitz: el archivo y el testigo: homo sacer: vol. III. Valencia: Pre-Textos, 2002. I88p.

[3] ALENGAR, S. L. de S. A experiência do luto em situação de violência: entre duas mortes. Tese (Doutorado em Psicologia Social) - Pontifícia Universidade Católica de São Paulo, São Paulo, 201 I.

[4] BERTA, S. L. O exílio: vicissitudes do luto: reflexões sobre o exílio político dos argentinos (I976-I983). I32 p. Dissertação (Mestrado em Psicologia Clínica) - Universidade de São Paulo, São Paulo, 2007.

[5] Um estudo psicanalítico sobre o trauma de Freud a Lacan. Tese (Doutorado em Psicologia Clínica) - Universidade de São Paulo, São Paulo, 2012.

[6] BERTA, S. L.; ROSA, M. D. Angústia e luto no exílio político. Revista Textura, São Paulo, ano 5, n. 5 , p. 52-56, 2005.

[7] FREUD, S. Luto e melancolia. Rio de Janeiro: Imago, I974. 396 p. (Edição standard brasileira das Obras Psicológicas Completas de Sigmund Freud, v. XIV). Tradução sob a direção de Jayme Salomão.

[8] HASSOUN, J. Los contrabandistas de la memoria. Buenos Aires: Ediciones de la Flor S. R. L., I996. I92 p. (Colección Inconsciente y Cultura).

[9] LACAN, J. A ciência e a verdade (I966). In: Escritos. Rio de Janeiro: Jorge Zahar, I998. p. I8. Tradução de Vera Ribeiro.

[IO] - A direção do tratamento (I958). In: Escritos. Rio de Janeiro: Jorge Zahar, I998. p. 593. Tradução de Vera Ribeiro.

[II] . Função e campo da fala e da linguagem em psicanálise (I953). In:_. Escritos. Rio de Janeiro: Jorge Zahar, I998. p. 238-323. Tradução de Vera Ribeiro.

[I2] _. O desejo e sua interpretação: seminário I958-I959. Porto Alegre: Associação Psicanalítica de Porto Alegre, 2002. Tradução da Associação Psicanalítica de Porto Alegre a partir do texto estabelecido pela Association Freudienne Internationale.

[I3] O O seminário: Livro II: Os quatro conceitos fundamentais da Psicanálise (I964). Rio de Janeiro: Jorge Zahar, I993. Tradução M. D. Magno. 
[I4] L_. Le seminaire: livre I4: La logique du fantasme, r966-r967. Inédito

[I5] PUJÓ, Mario Trauma y desamparo. Revista Psicoanálisis y el Hospital, Buenos Aires, vol. I7, p. 29, 2000.

[I6] ROSA, M. D. Escutando vidas secas. In: ASSOCIAÇÃO PSICANALÍTICA DE PORTO ALEGRE. (Org.). Adolescência: um problema de fronteiras. Porto Alegre: APPOA, 2004, p.I8.

[I7] ROSA, M. D.; BERTA, S. L.; ALENCAR, S. L. S. A elaboração coletiva do trauma: a clinica do traumático. In: SCOTTI, S. et al. (Org.). Escrita e Psicanálise II. Curitiba: CRV, 2OIO. v. I, p. I5-25.

[i8] ROSA, M. D.; BERTA, S.; CARIGNATO, T.; Alencar, S. A condição errante do desejo e a prática psicanalítica clínico-política. Revista Latino-Americana de Psicopatologia Fundamental, São Paulo, vol. I2, n. 3, p. 497-5II, set. 2009.

[ig] ROSA, M. D.; DOMINGUES, E. O método na pesquisa psicanalítica de fenômenos sociais e políticos: a utilização da entrevista e da observação. Psicologia \& Sociedade, Belo Horizonte, v. 22, n. I, p. I8O-I88, 2010.

[20] ROSA, M. D.; GAGLIATO, M. Psicanalistas, heróis e resistências. In: PERDOMO, M. G. e CERRUTI, M. (Org.). Trauma, memória e transmissão: a incidência da política na clínica psicanalítica. São Paulo: Primavera Editorial, 2OII.

[2I] ROSA, M. D.; POLI, M. C. Experiência e linguagem: a psicanálise e as estratégias de resistência. Psicologia \& Sociedade, Belo Horizonte, v. 2I, p. 5-I2, 2009. Número especial.

[22] SOLER, C. Trauma e fantasia. Stylus: Revista de Psicanálise, Rio de Janeiro, n. 9, p. 4559, out. 2004.

[23] ŽIŽEK, S.; DALY, G. Arriscar o impossível: conversas com Žižek. São Paulo: Martins Fontes, 2006. 2IIp. (Coleção Dialética). 